\title{
Determination of chloride diffusivity through partially saturated Portland cement concrete by a simplified procedure
}

\author{
A.T.C. Guimarães ${ }^{a}$, M.A. Climent ${ }^{\mathrm{b}, *}$, G. de Vera ${ }^{\mathrm{b}}$, F.J. Vicente ${ }^{\mathrm{b}}$, F.T. Rodrigues ${ }^{\mathrm{a}}$, C. Andrade $^{\mathrm{c}}$ \\ a Department of Materials and Construction, Fundação Universidade Federal do Rio Grande, João Manoel 38/701, 96211-060 Rio Grande, RS, Brazil \\ ${ }^{\mathrm{b}}$ Department of Construction Engineering, Universitat d'Alacant, PO Box 99, 03080 Alacant/Alicante, Spain \\ ' Institute of Construction Sciences Eduardo Torroja, CSIC, C/Serrano Galvache s/n, 28033 Madrid, Spain
}

\section{A R T I C L E I N F O}

\section{Article history:}

Received 1 February 2009

Received in revised form 29 June 2010

Accepted 18 July 2010

Available online 16 August 2010

\section{Keywords:}

Diffusion

Chloride

Concrete

Humidity

Transport properties

\begin{abstract}
A B S T R A C T
A recently proposed methodology for measuring the diffusion coefficient of chloride ions through concrete partially saturated with water, has been applied to five high-early-strength Portland cement mortars. The method is based on putting solid $\mathrm{NaCl}$ in contact with the concrete surface during the diffusion test. The results obtained indicate a strong dependence of the diffusion coefficient on the water saturation degree. The ionic diffusivities through these mortars are higher than those obtained with the same approach for five pozzolanic cement mortars of similar compositions. It has been also shown that the proposed test methodology and a different one based on the interaction of $\mathrm{HCl}(\mathrm{g})$ with the tested concrete surface, can yield comparable results. The $D$ values obtained are of similar magnitude, and the same type of dependence on the water saturation degree is found through both methods, when applied to similar Portland cement concrete mixes with cement content of about $350 \mathrm{~kg} / \mathrm{m}^{3}$ and water/cement ratios between 0.5 and 0.6 .
\end{abstract}

(c) 2010 Elsevier Ltd. All rights reserved.

\section{Introduction}

It is known that chloride content and penetration depth into concrete are highly dependent on microclimatic conditions, including the relative humidity at the material surface [1]. The amount of pore water in concrete can greatly affect field performance and the transport properties of test specimens [2,3]. Ions can only diffuse through the liquid phase contained in the pore network of concrete. This means that ionic diffusion is more efficient through saturated pores, while it is more restricted through those only partially filled with water $[4,5]$. When the water content of concrete decreases, the diffusion process is hindered by the decrease of the number of porous channels, which have a continuity of pore solution [6], this implies a lengthening of the ionic diffusion pathways. Another contribution to the decrease of the ionic diffusion coefficients can be the rise of the interaction forces between cement paste and ions due to the decrease of the thickness of the adsorbed water layers [6,7].

Some studies have been dedicated to the theoretical and numerical analysis of ionic diffusion through partially saturated concrete $[8,9]$, and several works have been done on modelling the chloride ingress into these partially saturated concretes [6,10-15]. These latter works need to include into the mathemati-

\footnotetext{
* Corresponding author. Tel.: +34 965903707; fax: +34 965903678

E-mail address: ma.climent@ua.es (M.A. Climent).
}

cal models the dependence of the chloride $\left(\mathrm{Cl}^{-}\right)$diffusion coefficient with the moisture content of concrete, or with the relative humidity of the atmosphere in equilibrium with concrete. Nevertheless, only recently some test procedures have been proposed for experimentally determining the diffusivity of $\mathrm{Cl}^{-}$ions through unsaturated concrete, due to the difficulty of maintaining the water saturation degree of concrete during the test. Climent et al. [16-19] proposed a test method based on an instantaneous deposition of $\mathrm{Cl}^{-}$due to interaction of the concrete surface with gaseous $\mathrm{HCl}$ produced in PVC combustion. The boundary conditions inherent to this methodology imply that the $\mathrm{Cl}^{-}$content profiles derived from the tests must be adjusted to a particular solution of Fick's second law of diffusion [16,17]. Guimarães and Helene [20-24] developed a simplified testing procedure in which solid $\mathrm{NaCl}$ is put in contact with the concrete surface during the diffusion test. The $\mathrm{Cl}^{-}$content profiles derived from these tests must be adjusted to the habitual error-function solution of Fick's second law of diffusion [23]. Nielsen and Geiker [25] obtained an initial $\mathrm{Cl}^{-}$supply to the concrete surface by a temporal immersion in a concentrated $\mathrm{NaCl}$ solution, followed by a drying until recovering the initial mass of the specimens.

The objective of the present work is to obtain more data with the simplified procedure based on the interaction of the concrete surface with solid $\mathrm{NaCl}$ [20-24], and to compare these results with those obtained from experiments based on an instantaneous $\mathrm{HCl}$ deposition on the tested concrete surface [16-19]. This comparison 
would allow to check if both methodologies are able to yield similar results, in order to advance towards a proposal of an optimised test method for measuring ionic diffusion coefficients through partially saturated cementitious materials.

\section{Experimental}

\subsection{Materials}

The concretes tested were prepared using a high-early-strength and sulphate resistant cement, type CP V RS, according to Brazilian standards [26,27]. This cement had a content of fly ash of $12 \%$ by mass. Table 1 shows the composition and characteristics of the cement. The fine and coarse aggregates used were a quartzite sand with a $4.8 \mathrm{~mm}$ maximum size, and a granite gravel with a $19 \mathrm{~mm}$ maximum size, respectively. Tap water was used for all these mixes, without adding any plasticizer.

Five concrete mixes (H1-H5) were selected for this work. These mixes were designed to obtain medium compressive strengths at 28 days, (30-45 MPa), and using water/cement $(\mathrm{w} / \mathrm{c})$ ratios between 0.48 and 0.66 , cement contents between approximately $300 \mathrm{~kg} / \mathrm{m}^{3}$ and $420 \mathrm{~kg} / \mathrm{m}^{3}$, and aggregate/cement mass ratios in the range $4-6$. Table 2 shows the compositions of the mixes, and Table 3 shows some measured properties of the concretes in the fresh state (slump), and hardened state (bulk densities and mean compressive strengths both at 28 and 60 days). It can be appreciated from Tables 2 and 3 that the series H2, H1, H3 increases consistently both the w/c ratio from 0.48 to 0.66 and the aggregate/cement ratio from 4 to 6 , while the cement content is decreased from $419 \mathrm{~kg} / \mathrm{m}^{3}$ to $297 \mathrm{~kg} / \mathrm{m}^{3}$. These latter three mixes had all equal slump values of about $10 \mathrm{~cm}$. On the other hand, for series $\mathrm{H} 4, \mathrm{H} 1, \mathrm{H} 5$ the aggregate/cement ratio increases consistently from 4 to 6 and the cement content is decreased from $416 \mathrm{~kg} / \mathrm{m}^{3}$ to $304 \mathrm{~kg} / \mathrm{m}^{3}$, while keeping the $\mathrm{w} / \mathrm{c}$ ratio constant at an approximate value of 0.55 . These latter compositional conditions raised very different slump values in this series, ranging from $22.5 \mathrm{~cm}$ for

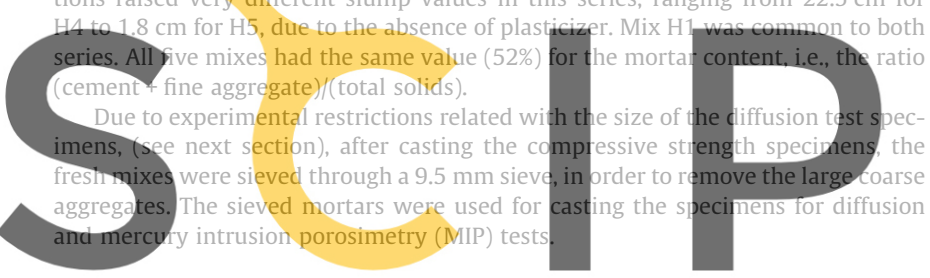

\section{Register for free at hatps//www scipedia com to}

\begin{tabular}{ll}
$\mathrm{CaO}$ & \\
$\mathrm{SiO}_{2}$ & 52.4 \\
$\mathrm{Al}_{2} \mathrm{O}_{3}$ & 23.3 \\
$\mathrm{Fe}_{2} \mathrm{O}_{3}$ & 7.2 \\
$\mathrm{MgO}$ & 3.3 \\
$\mathrm{~K}_{2} \mathrm{O}$ & 5.9 \\
$\mathrm{Na}_{2} \mathrm{O}$ & 1.06 \\
$\mathrm{SO}_{3}$ & 0.07 \\
$\mathrm{CO}_{2}$ & 3.3 \\
Ignition loss & 2.2 \\
Insoluble residue & 3.3 \\
Specific mass (g/cm & 32.8 \\
Fineness Blaine $\left(\mathrm{cm}^{2} / \mathrm{g}\right)$ & 12.99 \\
Setting start (h) & 5026 \\
Setting final (h) & $3: 56$ \\
Mortar compressive strength @ 28 days (MPa) & $5: 07$ \\
& 48.0 \\
\hline
\end{tabular}

Table 2

Composition of concrete mixes.

\begin{tabular}{lllll}
\hline Concrete & $\begin{array}{l}\text { Dosage (cement:fine } \\
\text { agg.:coarse agg.) }\end{array}$ & $\begin{array}{l}\text { Cement } \\
\text { content } \\
\left(\mathrm{kg} / \mathrm{m}^{3}\right)\end{array}$ & $\begin{array}{l}\text { Water/ } \\
\text { cement } \\
\text { ratio }\end{array}$ & $\begin{array}{l}\text { Aggregate/ } \\
\text { cement ratio }\end{array}$ \\
\hline $\mathrm{H} 1$ & $1: 2.12: 2.88$ & 355 & 0.55 & 5 \\
$\mathrm{H} 2$ & $1: 1.60: 2.40$ & 419 & 0.48 & 4 \\
$\mathrm{H} 3$ & $1: 2.64: 3.36$ & 297 & 0.66 & 6 \\
$\mathrm{H} 4$ & $1: 1.60: 2.40$ & 416 & 0.55 & 4 \\
$\mathrm{H} 5$ & $1: 2.64: 3.36$ & 304 & 0.57 & 6 \\
$\mathrm{H}-25^{\text {a }}$ & $1: 1.80: 3.27$ & 350 & 0.60 & 5.1 \\
$\mathrm{H}-35^{\text {a }}$ & $1: 1.89: 3.44$ & 350 & 0.50 & 5.3 \\
\hline
\end{tabular}

a Data corresponding to concretes tested in Ref. [17].
Table 3

Properties of concretes.

\begin{tabular}{lrlll}
\hline Concrete & Slump $(\mathrm{cm})$ & Bulk density $\left(\mathrm{kg} / \mathrm{m}^{3}\right)$ & $\begin{array}{l}\text { Compressive strength } \\
(\mathrm{MPa})\end{array}$ \\
\cline { 3 - 4 } & & & @ 28 days & @ 60 days \\
\hline H1 & 9.5 & 2220 & 39.2 & 46.3 \\
H2 & 10.0 & 2205 & 42.5 & 50.1 \\
H3 & 9.5 & 2170 & 29.4 & 37.2 \\
H4 & 22.5 & 2160 & 35.7 & 47.9 \\
H5 & 1.8 & 2250 & 36.3 & 45.6 \\
\hline
\end{tabular}

\subsection{Preparation and conditioning of diffusion specimens}

The procedures used for the conditioning and the diffusion tests are based on previous publications [20-24]. For each concrete mix 50 cylindrical specimens, $50 \mathrm{~mm}$ in height and $30 \mathrm{~mm}$ in diameter, were cast using the corresponding sieved mortar. These specimens were demoulded after $24 \mathrm{~h}$, and cured for 28 days in a wet chamber. After curing, the specimens were kept under laboratory environment until reaching 150 days age from casting. At this age six mortar specimens corresponding to each mix were tested for obtaining their bulk densities, water absorptions in immersion after boiling and dry masses [28]. All these data are necessary for calculating and controlling the water saturation degrees of the diffusion test specimens.

At 165 days age, and for each mix, four groups of six mortar specimens were formed choosing specimens randomly. Each group corresponds to one of the following water saturation degrees: $50 \%, 75 \%, 90 \%$ and $100 \%$. The specimens were stabilised at their corresponding saturation state either by drying in an oven at $50^{\circ} \mathrm{C}$ $[2,17]$, or by wetting with distilled water until getting the adequate mass. The water
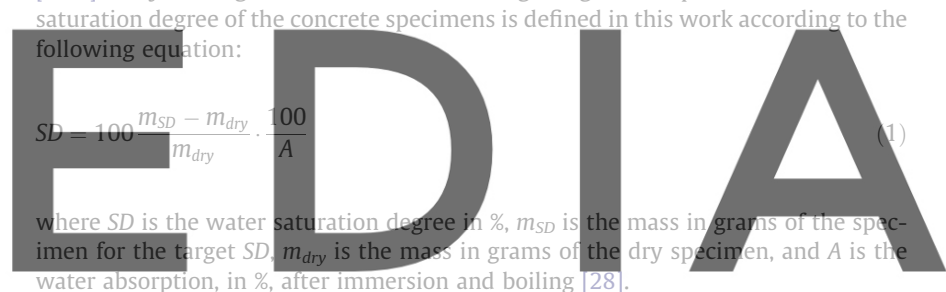

After getting the target SD, the specimens were allowed to equilibrate and Gomogenize theirmpisture content during a minimum of anonth in the following perfectly closed by heating, and extracting as much air as possible; the saturated specimens were stored in a desiccator partially immersed in a saturated $\mathrm{Ca}(\mathrm{OH})_{2}$ solution, The part of the specimens penetrated by chlorides during the diffusion tests remained above the liquid level.

\subsection{Chloride diffusion tests}

The chloride source in this methodology is ground solid $\mathrm{NaCl}$ (passing number 100 sieve) deposited at 199 days age (from casting) onto the surface test, which was always the lower (mould) surface of the cylindrical mortar specimens. For the nonsaturated specimens the deposited $\mathrm{NaCl}$ was protected with water-proof tape, and the specimens were again closed with three plastic layers. For the saturated specimens a pool of plastic tube was attached to the top, and the solid $\mathrm{NaCl}$ was deposited within the pool, in order to avoid the falling of a chloride solution over the lateral surface of the mortar cylinders, due to water condensation at the top during the diffusion experiment, Fig. 1.

The diffusion times for these tests were chosen according to previous experiences [20-24], and were set at: 7 days, 16 days, 21 days and 130 days, for the $100 \%, 90 \%, 75 \%$ and $50 \%$ SD, respectively. After completion of these periods the remaining $\mathrm{NaCl}$ at the top of the specimens was removed, and the surface cleaned with compressed air. Immediately, the specimens were submitted to a grinding process with a lathe, in order to obtain powdered concrete samples corresponding to thin successive parallel layers to the exposed surface of $2 \mathrm{~mm}$ thickness, up to a depth of $12 \mathrm{~mm}$. This latter maximum depth was chosen according to previous experience [20-24], showing that an adequately developed $\mathrm{Cl}^{-}$content profile can be obtained in these conditions for the diffusion times used in this work.

The powdered samples corresponding to a single depth step for the six specimens in each group, (same mortar and $S D$ ), were mixed in order to obtain an adequate concrete sample for the $\mathrm{Cl}^{-}$analysis, which was carried out by potentiometric titration [29]. All chloride concentrations in this work are expressed as\% $\mathrm{Cl}^{-}$relative to total mass. The results allowed to obtain representative $\mathrm{Cl}^{-}$content profiles of each mortar and SD value. Two samples of each mortar, were subjected to mercury intrusion porosimetry (MIP) tests at 240 days age, with a Micromeritics Autopore IV 9500 equipment. 


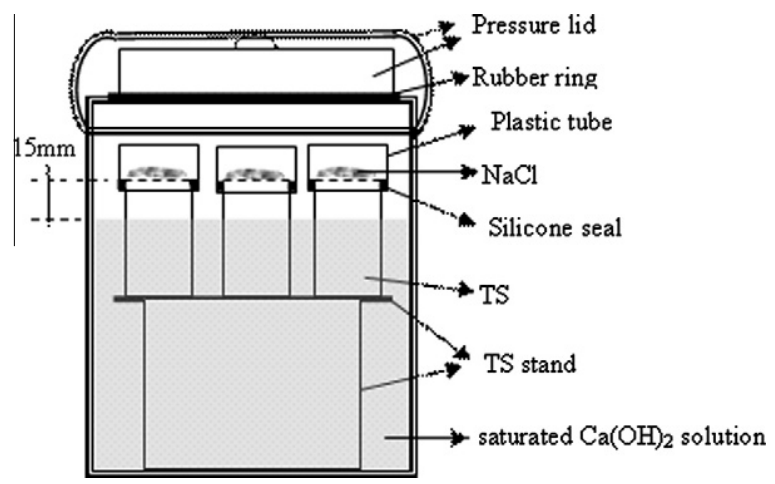

Fig. 1. Test specimens (TS) during diffusion experiments in saturated conditions.

\section{Results and discussion}

3.1. Analysis of the chloride content profiles and derivation of the diffusion parameters

The measured chloride content profiles obtained for $\mathrm{H} 1$ mortar are shown in Fig. 2. The $\mathrm{Cl}^{-}$profiles for the rest of the mortars, and their variations with SD are qualitatively similar to those shown in Fig. 2, but they are not shown here for the sake of conciseness. It is apparent from these profiles that chloride ions have penetrated considerably for SD values equal or higher than $75 \%$, while for

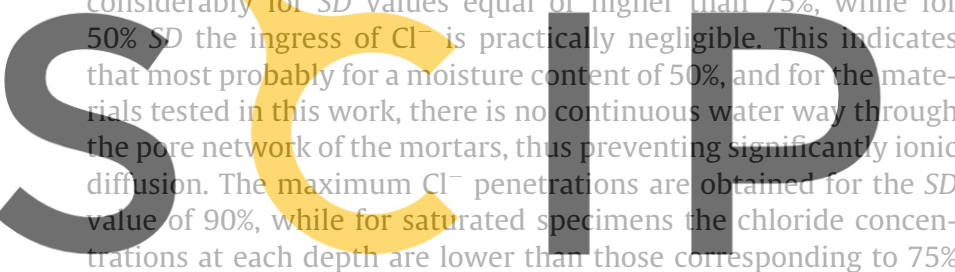
and $90 \%$ SD, see Fig. 2. This is due to the short duration of the dif

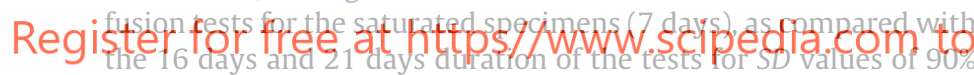
and $75 \%$, respectively.

All the experimental $\mathrm{Cl}^{-}$profiles have been fitted to the habitual error-function solution of Fick's second law of diffusion [30]:

$C(x, t)=C_{S} \operatorname{erfc}\left(\frac{x}{2 \sqrt{D t}}\right)$

where $C$ is the chloride concentration $\left(\% \mathrm{Cl}^{-}\right.$relative to total mass), $x$ is depth, $t$ is time, and the fitted parameters are $D$ (diffusion coefficient) and $C_{S}$ (surface concentration). In applying Eq. (2) it is assumed that the diffusion coefficient and the surface concentration have constant values. The results of the fittings are shown in

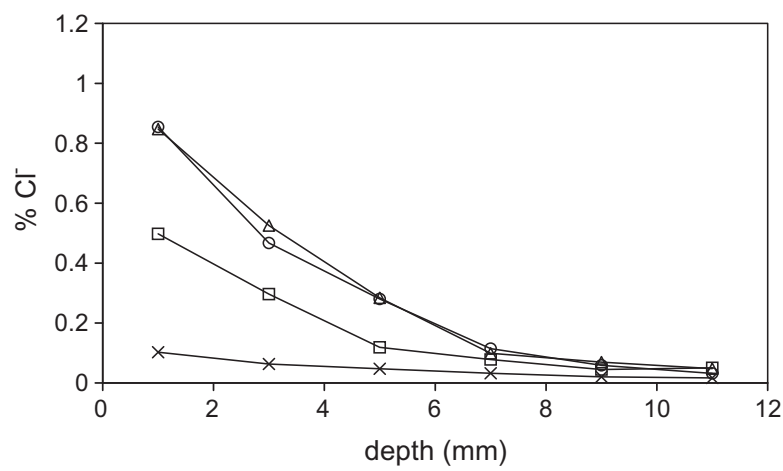

Fig. 2. Experimental chloride profiles for mortar $\mathrm{H} 1$ and water saturation degrees of approximately: 50\% (cross), 75\% (circle), 90\% (triangle), and saturated (square).
Table 4. Good correlation coefficients, higher than 0.95 , are obtained for all the cases.

It is appreciable from Table 4 that $D$ values increase steadily with the water saturation degree, reaching their maximum values at saturation. On the other hand, the calculated $C_{S}$ values are maximum for the $90 \% S D$ and are a little bit lower for the saturated states. This latter fact can also be attributed to the short duration of the diffusion tests for the saturated specimens.

\subsection{Dependence of the diffusion coefficients on the water saturation degree}

Data of diffusion coefficients against saturation degree for $\mathrm{H}$ mortars in Table 4 have been fitted, as suggested previously $[8,17]$, to polynomial equations of the form:

$D=a \cdot S D^{2}+b \cdot S D+c$

where $S D$ is the saturation degree in percentage and $D$ is the diffusion coefficient in $\mathrm{m}^{2} / \mathrm{s}$. Fitted parameters $a, b$, and $c$, and correlation coefficient for each mortar are shown in Table 5. Good correlation coefficients, higher than 0.96, are obtained for all cases. The fitting parameters of Table 5 are valid only for the materials studied in this work and in the range $44 \% \leqslant S D \leqslant 100 \%$.

Fig. 3 shows the dependences of the $\mathrm{Cl}^{-}$diffusion coefficients with the water saturation degree for the five mixes tested in this work (H1-H5) and for five similar families of mortars (P1-P5) pre-

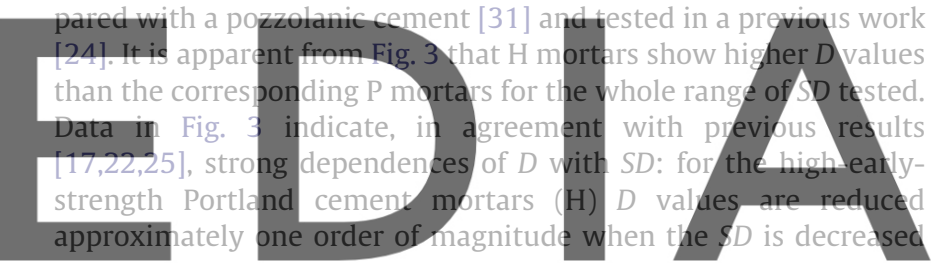

Table 5

Results of data fitting to Eq. (3).

\begin{tabular}{lllll}
\hline Mortar & $a$ & $b$ & $c$ & $r$ \\
\hline H1 & $4.4669 \times 10^{-15}$ & $-4.624 \times 10^{-13}$ & $1.402 \times 10^{-11}$ & 0.968 \\
H2 & $3.342 \times 10^{-15}$ & $-3.464 \times 10^{-13}$ & $1.044 \times 10^{-11}$ & 0.999 \\
H3 & $-5.995 \times 10^{-15}$ & $1.072 \times 10^{-12}$ & $-3.296 \times 10^{-11}$ & 0.997 \\
H4 & $-4.075 \times 10^{-15}$ & $7.770 \times 10^{-13}$ & $-2.498 \times 10^{-11}$ & 0.995 \\
H5 & $2.087 \times 10^{-15}$ & $-1.432 \times 10^{-13}$ & $7.296 \times 10^{-12}$ & 1.000 \\
\hline
\end{tabular}




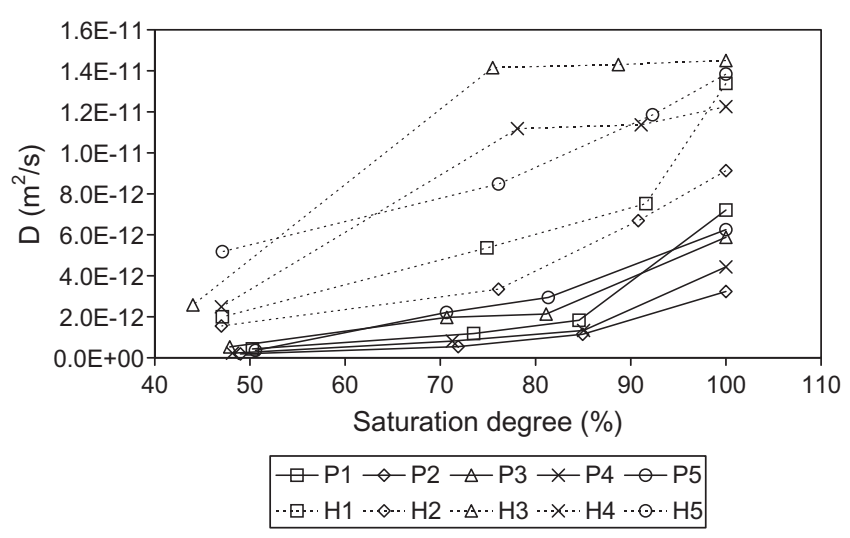

Fig. 3. Dependences of the measured chloride diffusion coefficients with the water saturation degree, for the mixes tested in this work (H1-H5), and for a similar family of mixes prepared with a pozzolanic cement (P1-P5) [24].

\section{from $100 \%$ to $50 \%$, while the reduction is not as high for the pozzo-} lanic cement mortars $(P)$. It is also worth pointing out that for some of the $\mathrm{H}$ mixes, especially $\mathrm{H} 3$ and $\mathrm{H} 4, \mathrm{D}$ values decrease only slightly in the range of SD between $100 \%$ and $75 \%$, while for the rest of $\mathrm{H}$ mortars and all P mixes the diffusion coefficient is strongly reduced in the same $S D$ range. All these facts can be attributed to the different porous microstructures of mortars $\mathrm{H}$ and $\mathrm{P}$, as it will be discussed later.

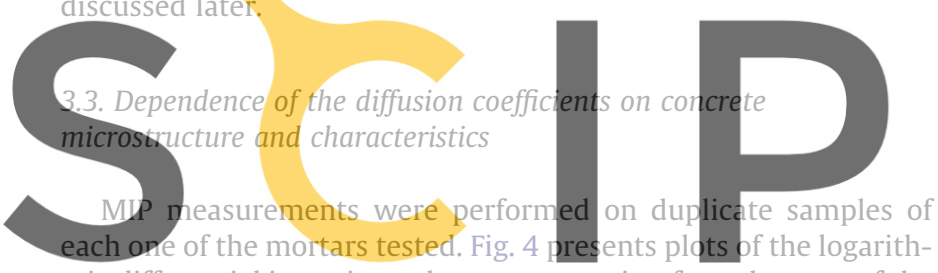
mic differential intrusion volume vs. pore size, for only some of the samples, since all H mortar samples show qualitatively similar

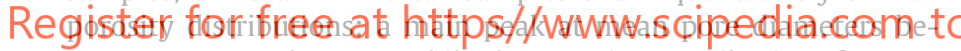
tween $57 \mathrm{~nm}$ and $84 \mathrm{~nm}$, while the porosity contributions for pore diameters higher than $200 \mathrm{~nm}$ are variable for the different $\mathrm{H}$ mortars. Totai porosities derived from IVIIP measurements are reported in Table 6, while Fig. 5 shows the quantitative distributions, expressed as percentages relative to the total pore volume, for three pore diameter ranges: diameters lower than $50 \mathrm{~nm}$ (this range includes the gel pores and the finest capillary pores); diameters between 50 and $200 \mathrm{~nm}$ (corresponds to the mid-range capillary

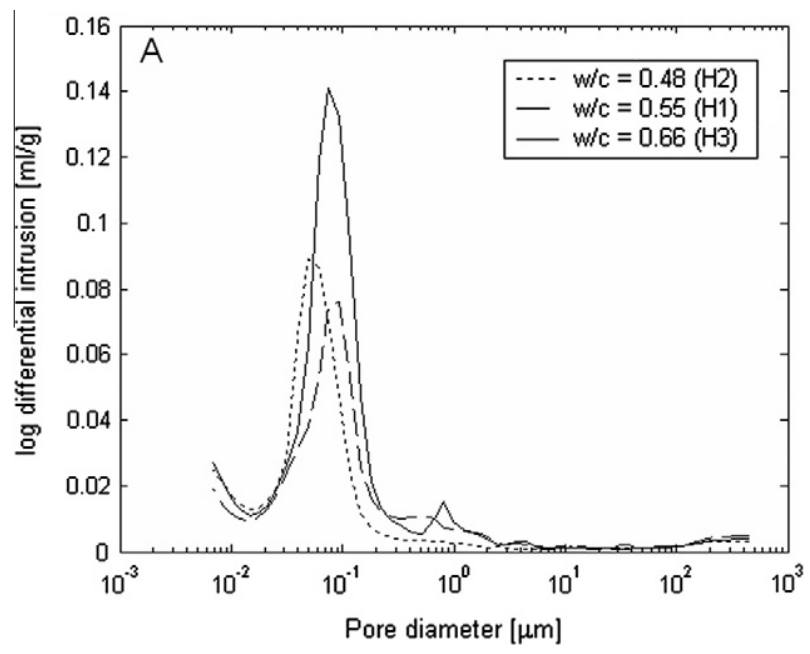

Fig. 4. Log differential intrusion curves of $\mathrm{H} 1, \mathrm{H} 2$ and $\mathrm{H} 3$ mortars.
Table 6

Total porosities of mortars, measured by MIP.

\begin{tabular}{llllll}
\hline Mix & H1 & H2 & H3 & H4 & H5 \\
\hline Porosity (\%) & 12.35 & 12.20 & 17.36 & 13.22 & 14.81 \\
\hline
\end{tabular}

porosity); and diameters higher than $200 \mathrm{~nm}$ (larger capillary and coarse pores) [32]. Fig. 5 also includes, for the sake of comparison, the percentage porosity distributions corresponding to the pozzolanic cement mortars $(\mathrm{P})$.

It has been analyzed if the proposed methodology is able to discriminate the ionic diffusion properties of concretes of different quality or composition. If it is considered only the mortar series $\mathrm{H} 2, \mathrm{H} 1, \mathrm{H} 3$, the obtained $D$ values increase consistently with the increasing values of $\mathrm{w} / \mathrm{c}$ ratio for the whole range of $S D$ tested, as shown in Table 4 and Fig. 3. This is as expected, since many previous results have indicated that a reduction in $w / c$ ratio leads to a significant reduction in diffusivity [33-35]. On the other hand, the mortar series $\mathrm{H} 4, \mathrm{H} 1$, H5, which increases the aggregate/cement ratio and decreases the cement content, while keeping the same $\mathrm{w} / \mathrm{c}$ ratio, does not show a systematic ranking of the $D$ values of these three mortars. H4 and H5 mortars are those introducing more variability in the ranking of $D$ values for this series, as it may be appreciated in Table 4 and Fig. 3. It is worth noting also that the ranking of $\mathrm{H}$ concretes according to their compressive strengths is different at 28 days and 60 days, (see Table 3), and this

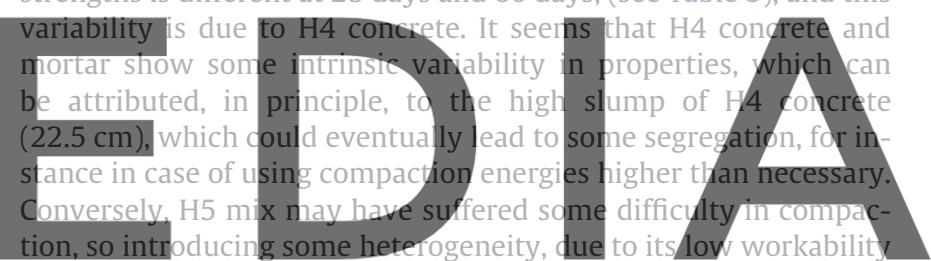

(1.8 cm slump in Table 3).

A more clear explanation of the rankings of diffusivities for $\mathrm{H}$

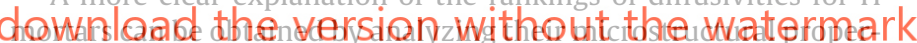
ties. Figs. 4 and 5 show that $\mathrm{H} 2$ mortar has a more refined porous network, with higher proportion of pores of low diameter and lower total porosity (Table 6), than the rest of $\mathrm{H}$ mortars, as a consequence of having the lowest $\mathrm{w} / \mathrm{c}$ ratio (0.48). Fig. 5 indicates that the rest of $\mathrm{H}$ mortars show more similar pore diameter distributions. For the pore range diameters between $50 \mathrm{~nm}$ and $200 \mathrm{~nm}$ (mid-range capillary porosity) the percentage porosities (referred to total pore volume) are $45.9 \%, 50.4 \%, 58.3 \%, 60.1 \%$ and $63.0 \%$, for the H2, H1, H4, H5 and H3 mortars, respectively. These values show the same ranking as that of total porosities in Table 6, and that corresponding to $D$ values at $90 \% S D$ (Fig. 3). It may be concluded that $\mathrm{Cl}^{-}$diffusion coefficients at partial water saturation states are related to the microstructural properties of $\mathrm{H}$ mortars, especially the total porosity and the percentage of porosity corresponding to mid-range capillary pores.

The comparison of pore size distributions of $\mathrm{H}$ and $\mathrm{P}$ mortars in Fig. 5 allows to understand the different ionic diffusion properties, at the whole $S D$ range tested, of both mortar series. P mortars show always higher percentages of porosity falling in the pore diameter range below $50 \mathrm{~nm}$ (gel and smallest capillary pores) than $\mathrm{H}$ mortars. Conversely, $\mathrm{H}$ mortars show always higher percentages of porosity falling in the pore diameter ranges between $50 \mathrm{~nm}$ and $200 \mathrm{~nm}$ (mid-range capillaries), and higher than $200 \mathrm{~nm}$ (large capillaries and coarse pores), than P mortars. The more refined porous network of P mortars accounts for the systematically lower $D$ values of these mixes, as compared with $\mathrm{H}$ mortars in Fig. 3. Only $\mathrm{H} 2$ mortar, whose porosity distribution is more close to those of $\mathrm{P}$ mortars, shows diffusion coefficients slightly higher than the corresponding values for P mortars. 


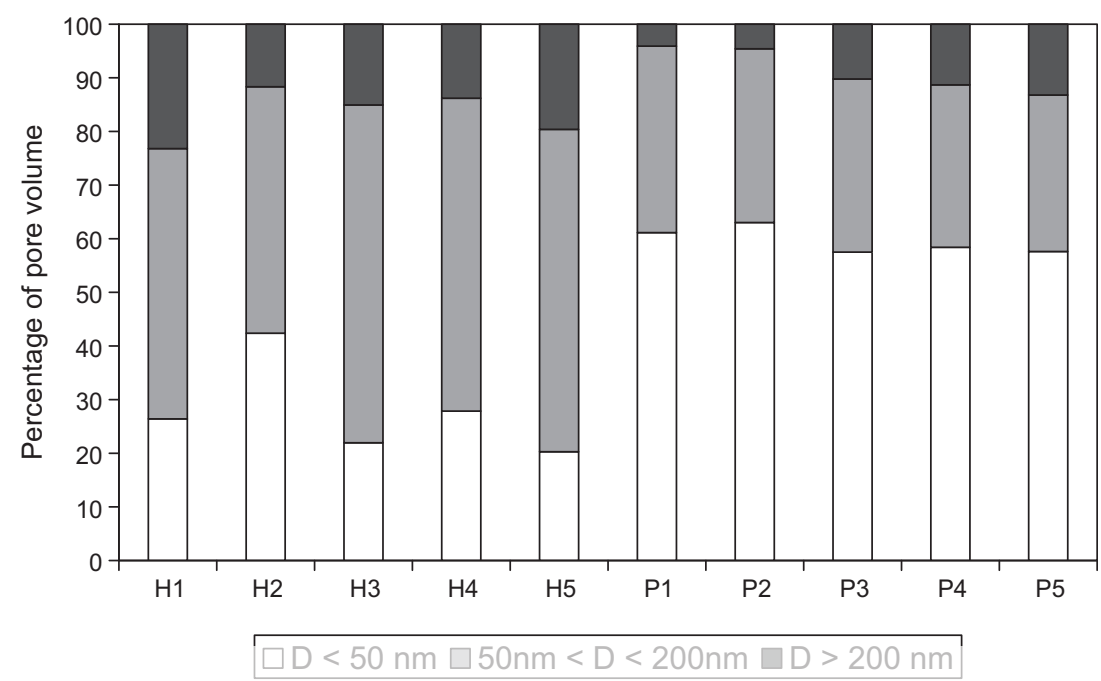

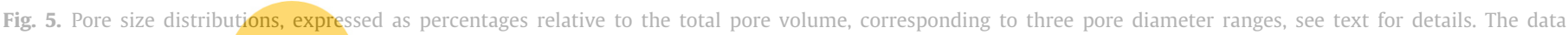
correspond to the mortars tested in this work (H1-H5), and to a similar family of mortars prepared with a pozzolanic cement (P1-P5) [24],

3.4. Comparison of $D$ values with those obtained through an alternative method
$D=2.336 \times 10^{-15} S D^{2}-1.380 \times 10^{-13} S D+2.437 \times 10^{-12} r=0.976$

(5)
The results reported in this work can be compared with those

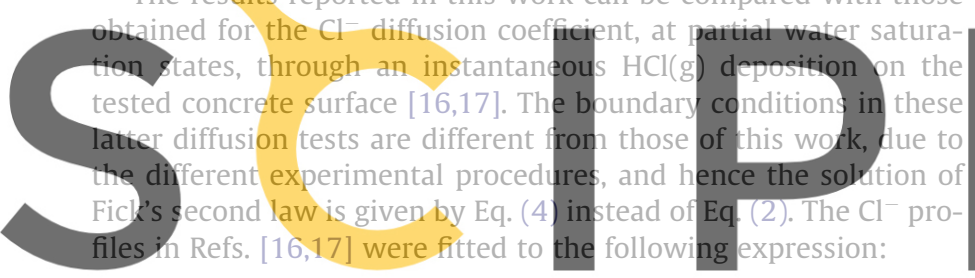

\section{Register forrfree at Attps//www.scipedia.com to}

The fitted parameters are diffusion coefficient $D\left(\mathrm{~m}^{2} / \mathrm{s}\right)$ and total chloride deposited $m\left(\mathrm{~kg} / \mathrm{m}^{2}\right)$ which remain constant during the test $[16,17]$. In these latter works two concretes (H-25 and H-35) were tested, whose mean compressive strengths at 28 days were 27.9 MPa and 40.8 MPa, respectively [17]. The details of composition of these mixes, also included in Table 2, indicate that their characteristics are rather similar to those of mix $\mathrm{H} 1$ in this work. Fig. 6 , plotting together the obtained $D$ values vs. saturation degrees, indicates that the three data sets (H1, H-25 and $\mathrm{H}-35)$ show a similar dependence with the water saturation degree, which can be fitted to the following polynomial function (solid line in Fig. 6):

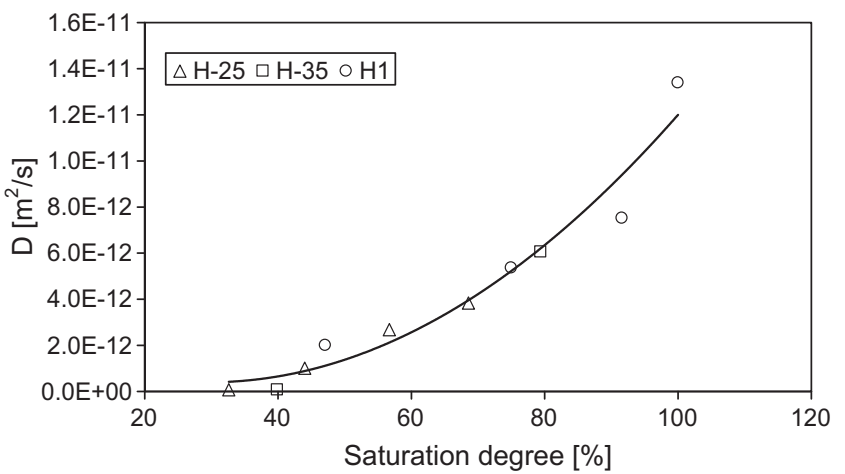

Fig. 6. Comparison of chloride diffusion coefficients at different water saturation degrees. The data correspond to different types of samples, see text for details, and were obtained using two different methodologies: $\mathrm{H}-25$, and $\mathrm{H}-35$ data come from Ref. [17], while H1 data correspond to this work. where $D$ is expressed in $\mathrm{m}^{2} / \mathrm{s}$ and $S D$ in \%. It is worth to recall that used in this work. Furthermore, the specimens tested ir these latter
references were concrete sainples, while those of this work are mor-
tar samples sieved from concretes. Nevertheless, the good agree-
ment found in Fig. 6 seems to indicate that both approaches yield
comparable results. those corresponding to the gaseous $\mathrm{HCl}$ deposition on the concrete


the chemical species mainly acting in marine or de-icing salt environments to which concrete may be exposed. On the other hand, some drawbacks of this approach must be also considered: the boundary condition of constant surface $\mathrm{Cl}^{-}$concentration seems to be not rigorously fulfilled during the tests, if one consider the variation of $C_{S}$ values (Table 4) and the different development of the $\mathrm{Cl}^{-}$content profiles for different durations of the diffusion tests (Fig. 2). Another fact to be taken into account is the almost negligible amount of ingressed $\mathrm{Cl}^{-}$for low $\mathrm{SD}$ of about $50 \%$ (Fig. 2). The scarce development of the $\mathrm{Cl}^{-}$profiles at low saturation degrees, with very low concentrations at all depths, is likely to lower the reliability of the $D$ values derived from such profiles. Further research is in progress to compare chloride diffusion coefficients obtained through both abovementioned approaches, using the same concrete samples and the same conditioning procedures previous to diffusion tests, in order to confirm the concordance of results.

\section{Conclusions}

It is possible to obtain experimental values for the $\mathrm{Cl}^{-}$diffusion coefficients through concrete, at water saturation degrees between $50 \%$ and $100 \%$, using a simplified methodology based on putting solid $\mathrm{NaCl}$ in contact with the concrete surface during the diffusion test.

The results obtained for five high-early-strength Portland cement mortars indicate a strong dependence of $D$ with $S D$. The ionic diffusivities through these mortars are higher than those obtained with the same approach for five pozzolanic cement mortars of similar compositions. This latter difference of properties and the rank- 
ings of $D$ values of the mortars tested in this work, can be related to differences in the microstructural properties of the mortars, mainly their total porosity and pore size distributions.

It has been shown that the proposed test methodology and a different one based on the interaction of $\mathrm{HCl}(\mathrm{g})$ with the tested concrete surface, can yield comparable results, i.e., $D$ values of similar magnitude and the same type of dependence on the water saturation degree, when applied to similar Portland cement concrete mixes with cement content of about $350 \mathrm{~kg} / \mathrm{m}^{3}$ and water/cement ratios between 0.5 and 0.6 .

\section{Acknowledgements}

We thank the funding received for this research from the Ministerio de Ciencia e Innovación of Spain and Fondo Europeo de Desarrollo Regional (FEDER) through Project BIA2010-20548. Dr. A.T.C. Guimarães makes acknowledgements of the funds received from the Research and International Relations Vice-Chancellorships of the University of Alicante, (Grants INV07-19 and Programa Propio de Fomento de las Relaciones Internacionales) for a temporal stay at the Department of Construction Engineering of this University (July 2007).

\section{References}

[1] Mehta PK, Schiessl P, Raupach M. Performance and durability of concrete systems. Congress reports, vol. I. In: 9th Int congress on the chemistry of cement: national council for cement and building materials (NCB), New Delhi.

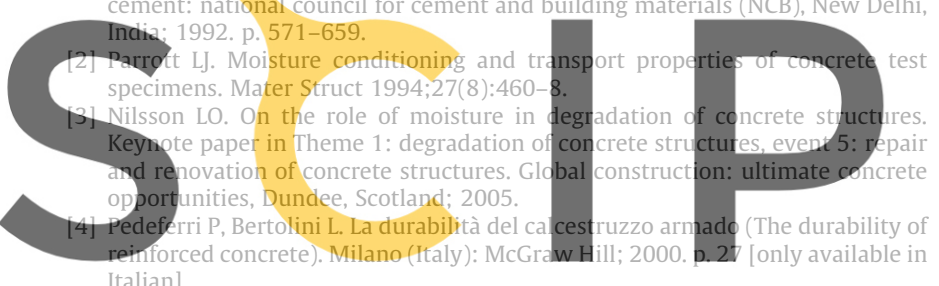
Italian

[5] Chatterji S. On the non-applicability of unmodified Fick's law to ion transport

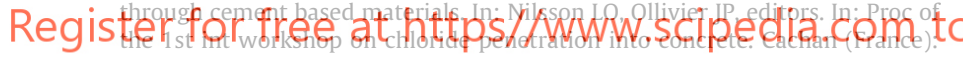
RILEM Publications; 1997. p. 64-73.

[6] Saetta AV, Scotta RV, Vitaliani RV. Analysis of chloride diffusion into partially saturated concrete. ACI Mater J 1993;90(5):441-51.

[7] Quenard D, Sallee $H$. Water vapour adsorption and transfer in cement-based materials: a network simulation. Mater Struct 1992;25(9):515-22.

[8] Martys NS. Diffusion in partially-saturated porous materials. Mater Struct 1999;32(8):555-62.

[9] Nilsson LO. A numerical model for combined diffusion and convection of chloride ion in non-saturated concrete. In: Andrade C, Kropp J, editors. Proc of the 2nd int workshop on testing and modeling the chloride ingress into concrete. Cachan (France): RILEM Publications; 2000. p. 261-75.

[10] Swaddiwudhipong S, Wong SF, Wee TH, Lee SL. Chloride ingress in partially and fully saturated concretes. Concr Sci Eng 2000;2:17-31.

[11] Meijers SJH, Bijen JMJM, de Borst R, Fraaij ALA. Chloride ingress modelling: comparison of experimental and numerical data. In: Andrade C, Kropp J, editors. Proc of the 3rd int workshop on testing and modelling the chloride ingress into concrete. Cachan (France): RILEM Publications; 2004. p. 329-45.

[12] Meijers SJH, Bijen JMJM, de Borst R, Fraaij ALA. Computational results of a model for chloride ingress in concrete including convection, drying-wetting cycles and carbonation. Mater Struct 2005;38(2):145-54.

[13] Samson E, Marchand J, Snyder KA, Beaudoin JJ. Modeling ion and fluid transport in unsaturated cement systems in isothermal conditions. Cem Concr Res 2005;35(1):141-53.
[14] Oh BH, Jang SY. Effects of material and environmental parameters on chloride penetration profiles in concrete structures. Cem Concr Res 2007;37(1):47-53.

[15] Nguyen TQ Petković J, Dangla P, Baroghel-Bouny V. Modelling of coupled ion and moisture transport in porous building materials. Constr Build Mater 2008;22(11):2185-95.

[16] Climent MA, de Vera G, López JF, García C, Andrade C. Transport of chlorides through non-saturated concrete after an initial limited chloride supply. In: Andrade C, Kropp J, editors. Proc of the 2nd int workshop on testing and modelling the chloride ingress into concrete. Cachan (France): RILEM Publications; 2000. p. 173-87.

[17] Climent MA, de Vera G, López JF, Viqueira E, Andrade C. A test method for measuring chloride diffusion coefficients through non-saturated concrete. Part I: the instantaneous plane source diffusion case. Cem Concr Res 2002;32(7): 1113-23.

[18] de Vera G, Climent MA, López JF, Viqueira E, Andrade C. Transport and binding of chlorides through non-saturated concrete after an initial limited chloride supply. In: Andrade C, Kropp J, editors. Proc of the 3rd int workshop on testing and modeling the chloride ingress into concrete. Cachan (France): RILEM Publications; 2004. p. 205-18.

[19] de Vera G, Climent MA, Viqueira E, Antón C, Andrade C. A test method for measuring chloride diffusion coefficients through partially saturated concrete. Part II: the instantaneous plane source diffusion case with chloride binding consideration. Cem Concr Res 2007;37(5):714-24.

[20] Guimarães ATC. Vida útil de estructuras de concreto armado em ambientes marítimos (Service life of reinforced concrete structures in marine environments). Ph.D. Thesis, Universidade de São Paulo, PCC/USP, Engenharia Civil, São Paulo, Brasil; 2000 [only available in Portuguese].

[21] Guimarães ATC, Helene PRL. The moisture effect on the diffusion of chloride ions in hydrated cement paste. In: Dean CSW, Degadillo GH, Bushman JB, editors. Proc of the int symp on marine corrosion in tropical environments, ASTM STP 1399, Philadelphia, USA; 2000. p. 135-49.

[22] Guimarães ATC, Helene PRL. Chloride diffusion and the influence of the saturation degree of the concrete. In: Andrade C, Kropp J, editors. Proc of the 3rd int workshop on testing and modeling the chloride ingress into concrete. Cachan (France): RILEM Publications; 2004. p. 237-56

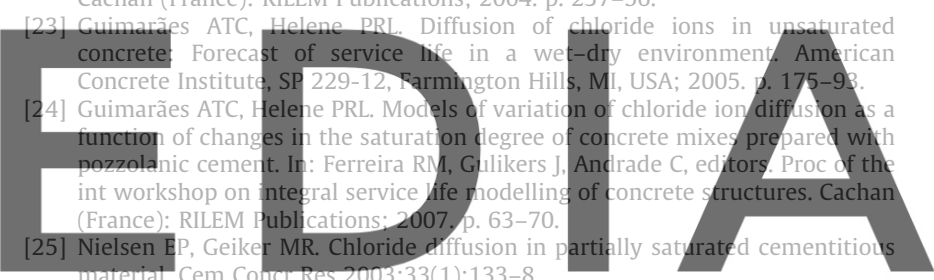

[26] Associação Brasileira de Normas Técnicas. Cimentos Portland de alta resistencia inicial (High-early-strength Portland cements) NBR-5733, Rio de dowirito tell the version without the watermark Sulfatos (Sulphate resistant Portland cements), NBR-5737, Rio de Janeiro: 1992.

[28] American Society for Testing of Miateriais. Standard test method for specific gravity, absorption and voids in hardened concrete, ASTM C 642/90. Annual Book of ASTM Standards, Philadelphia; 1990.

[29] Climent MA, Viqueira E, de Vera G, López-Atalaya MM. Analysis of acid-soluble chloride in cement, mortar, and concrete by potentiometric titration without filtration steps. Cem Concr Res 1999;29(6):893-8.

[30] Crank J. The mathematics of diffusion. Oxford (UK): Oxford University Press: 1975.

[31] Associação Brasileira de Normas Técnicas. Cimento Portland Pozolânico (Pozzolanic Portland cement), NBR-5736, Rio de Janeiro; 1991.

[32] Sánchez I, Nóvoa XR, de Vera G, Climent MA. Microstructural modifications in Portland cement concrete due to forced ionic migration tests. Study by impedance spectroscopy. Cem Concr Res 2008;38(7):1015-25.

[33] Page CL, Short NR, El Tarras A. Diffusion of chloride ions in hardened cement pastes. Cem Concr Res 1981;11(3):395-406.

[34] Atkinson A, Nickerson AK. The diffusion of ions through water-saturated cement. J Mater Sci 1984;19(9):3068-78.

[35] Garboczi EJ, Bentz DP. Computer simulation of the diffusivity of cement-based materials. J Mater Sci 1992;27(8):2083-92. 